\title{
Development of active power filter using rectifier boost technique
}

\author{
Dygku Aniqnatasa Awg Osman, Rahimi Baharom, Dalina Johari, Muhamad Nabil Hidayat, \\ Khairul Safuan Muhammad \\ Faculty of Electrical Engineering, Universiti Teknologi MARA, Malaysia
}

\begin{tabular}{|c|c|}
\hline Article Info & ABSTRACT \\
\hline Article history: & \multirow{8}{*}{$\begin{array}{l}\text { The development of active power filter (APF) using rectifier boost technique } \\
\text { has been identified to compensate for the pulsating nature of the distorted } \\
\text { supply current waveform of non-linear load. In this work, investigation is } \\
\text { carried out on the operation of rectifier without any filters function. This is } \\
\text { then extended to operate the rectifier converter with an active power filter } \\
\text { function. APF function is implemented by enabling the closed-loop control } \\
\text { using standard proportional integral control to rectify the distorted supply } \\
\text { current to become continuous, sinusoidal and in-phase with the supply } \\
\text { voltage waveform. Consequently, the total harmonic distortion (THD) level } \\
\text { was reduced to meet the acceptable limit defined in the standard of IEEE-519 } \\
\text { 1992. The selected simulation results obtained from MATLAB/Simulink are } \\
\text { presented to justify the proposed filter structure. }\end{array}$} \\
\hline Received Aug 27, 2018 & \\
\hline Revised Jan 25, 2019 & \\
\hline Accepted Mar 15, 2019 & \\
\hline Keywords: & \\
\hline Active power filter & \\
\hline Boost rectifier & \\
\hline $\begin{array}{l}\text { Non-linear load } \\
\text { Rectifier }\end{array}$ & \\
\hline
\end{tabular}

Copyright (c) 2019 Institute of Advanced Engineering and Science. All rights reserved.

\section{Corresponding Author:}

Rahimi Baharom, Faculty of Electrical Engineering, Universiti Teknologi MARA, 40450 Shah Alam, Selangor, Malaysia.

Email: rahimi6579@gmail.com

\section{INTRODUCTION}

The demand for high power quality, power supply system has shown an increase in recent years. This trend reflects in the increase use of active power filter to provide high power factor operation with low total harmonic distortion (THD) level of input current waveform, resulting in power quality problems [1-12]. It is a variation of voltage, frequency and waveform. A significant phase difference between current and voltage waveform leads to low power factor.

Currently, there are various methods to mitigate power quality problems such as STATCOM, hybrid filters, passive power filter, and active power filter. In comparison to other filters, passive power filter would be seen as a common industrial technique to resolve power quality problems. However, the use of passive power filter during design stage tend to cause dissatisfaction due to its main drawback which is the limitation of frequencies reduction [8]. Besides, in many situations, the requirement of reactive power at fundamental frequency would be lower and the design of passive filters could be very challenging to reduce rms current of the supply where the dominance is of the harmonic currents [13-19].

On the other hand, active power filter has been identified to overcome the passive power filter drawbacks with consideration to input and output loading. The main purpose of the active power filters is the capability to form continuous sinusoidal line current to reduce semiconductor components, and coupling transformers. The usage of active power filter is less common in industry field compared to passive power filter due its higher cost. However, the unknown advantage of active power filter is proven to be more beneficial where it can filter the harmonic simultaneously, less design stage as harmonic study not compulsory, and filter power is easier [8]. 
In recent years, various active power filter (APF) configurations have been proposed to solve power quality problem such as harmonic problems. It have been classified into series, shunt and hybrid active power filters. There were many studies regarding the control strategies, configuration and application of active power filter including the voltage source inverter (VSI) or current source inverter (CSI) operation. The methods introduced on these converter topologies are boost rectifier circuit in which one of the simplest technique and form that contains adjustment of a basic bridge-diode circuit by insertion of boost switch and inductor. Based on analysis observation on these conceptual studies, this converter offers more benefits such as sinusoidal input current, unity power factor on the source side and a simpler power circuit compared to other circuit topologies [11].

The proposed ac-dc converter will be able to provide almost unity power factor during wide variations of the rectifier load. Fundamentally, boost rectifier produces higher DC output voltage from an input of AC voltage. Thus, inductor will be used at the input to provide an additional voltage source in series with the supply [9].

Typically, this method is widely used in various applications due to its respective features like high switching rates, and high power rating. In addition to that, boost rectifiers are also commonly used in electric drives, Switching-Mode Power Supply (SMPS), Uninterruptible Power Supply (UPS) and power factor corrector devices [20-25] Therefore, in this paper, an attempt is made to review the circuit topology and simulation modeling performed on active power filter (APF) using boost rectifier simulated in MATLAB/Simulink.

\section{RESEARCH METHOD}

The step-by-step procedure for the study is shown in Figure 1. The flowchart begins with the research and study about various types of power quality and its problems. Harmonic distortion has been identified as the main cause of power quality problems. Next, one of the techniques or methods to rectify power quality problems was identified, which is with active power filter using rectifier boost technique. Then, the design analysis of the proposed filter which is APF to obtain the desired low value of THD level is simulated using MATLAB/Simulink. However, after the circuit execution, the THD level without filter appeared to be exceeding the limit of harmonic based on IEEE519 standard. Thus, the design of active power filter using rectifier boost technique was developed to ensure the harmonic level is comply with the IEEE 519 standard.

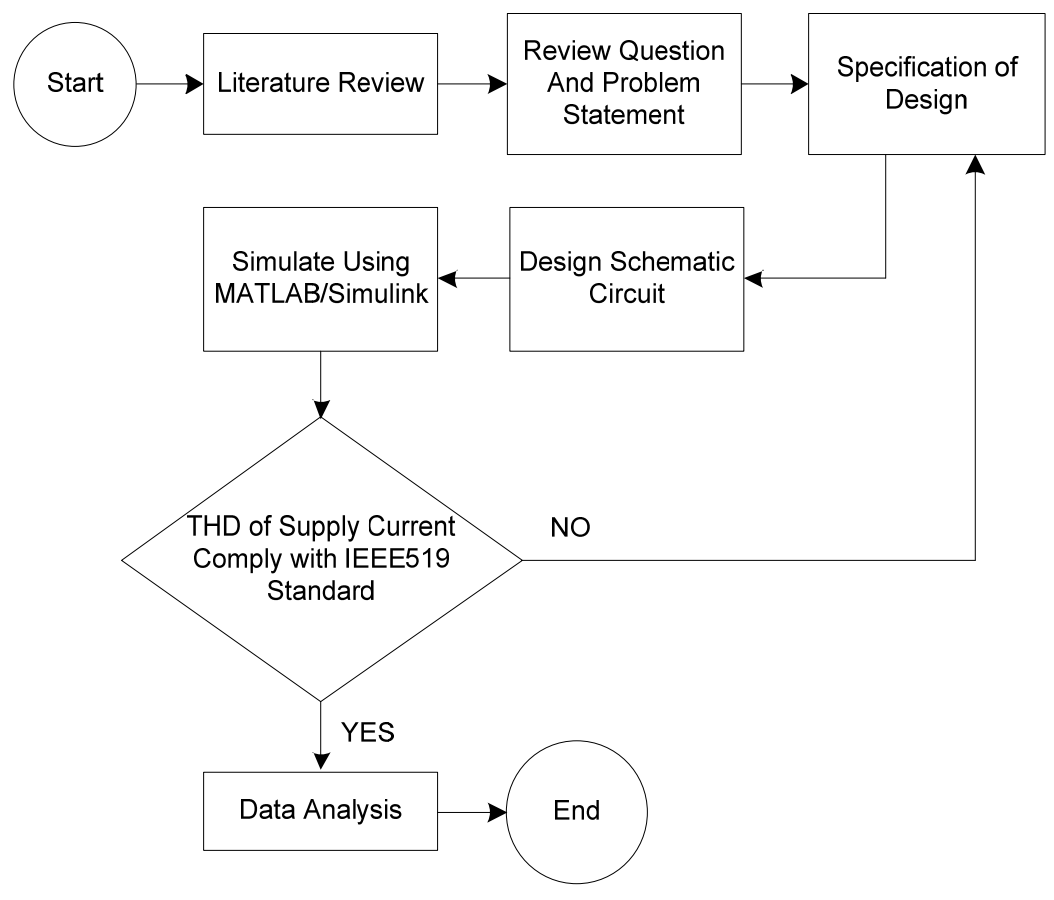

Figure 1. Overall flowchart of project 


\section{PROPOSED APF WITH RECTIFIER BOOST TECHNIQUE}

In this paper, APF with boost rectifier technique has been proposed. The main objective of this technique is to filter out harmonics in the power system while correcting the supply current waveform of the non-linear load.

The circuit topology of APF implemented with boost rectifier circuit is shown in Figure 2. The configuration consists of inductors, capacitors, resistor, diode-bridge, power switching device, and current control loop (CCL). Meanwhile, the components inside CCL are subtractor, reference current, Proportional-Integral (PI) controller, comparator and carrier signal.

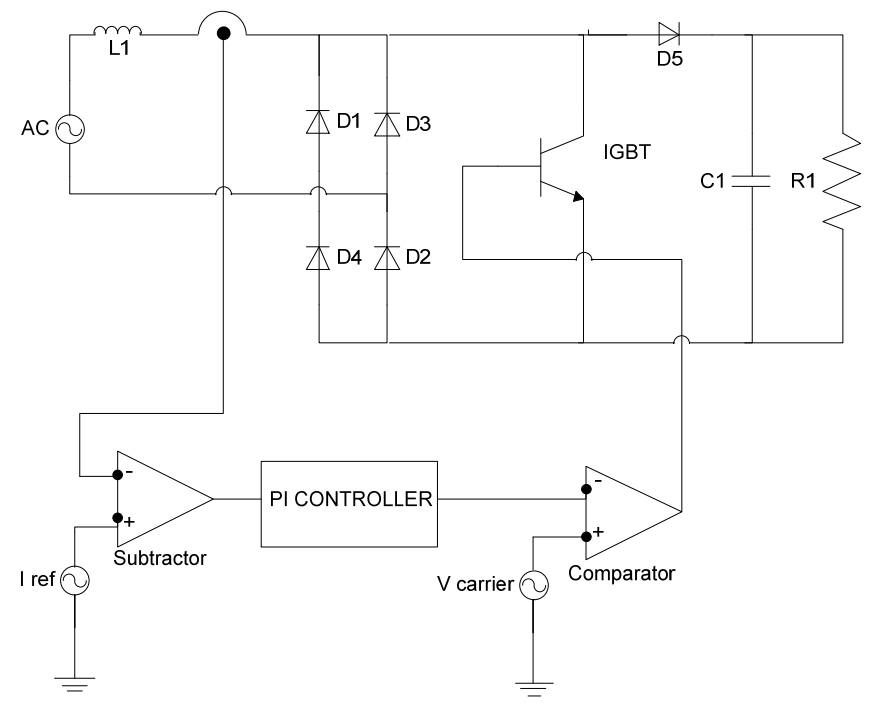

Figure 2. APF using boost rectifier topology

\section{COMPUTER SIMULATION MODEL}

The computer simulation model of the proposed converter starts with the design of the rectifier interconnection with power supply and a capacitive load. This circuit was implemented without any filter. The proposed configuration technique model is shown in Figure 3. Initially, the supply current passes through the subtractor that acts to create an error signal. Next, the signal passes through the PI controller to eliminate an error signal. Finally, a comparator was used to produce an active pulse width modulation (APWM) by comparing the modulating signal with the carrier signal. The modeling of a step response as shown in Figures 4 and 5 were also developed to investigate that the supply current will track the variation value of reference current, thus verify the proposed APF function. The Circuit specifications detail is shown in Table 1.

\begin{tabular}{cc}
\multicolumn{2}{c}{ Table 1. Circuit specifications } \\
\hline System Parameters & Values \\
\hline Input voltage, $V_{s}$ & $40 \mathrm{~V}_{\mathrm{rms}}$ \\
Line inductor, $L_{s}$ & $1 \mathrm{mH}$ \\
Output capacitor, $C_{o}$ & $1000 \mu \mathrm{F}$ \\
Resistive load, $R$ & $300 \Omega$ \\
Switching frequency, $f_{s}$ & $50 \mathrm{kHz}$ \\
Proportional gain, $K_{p}$ & 20 \\
Integral gain, $K_{i}$ & 1000 \\
\hline
\end{tabular}




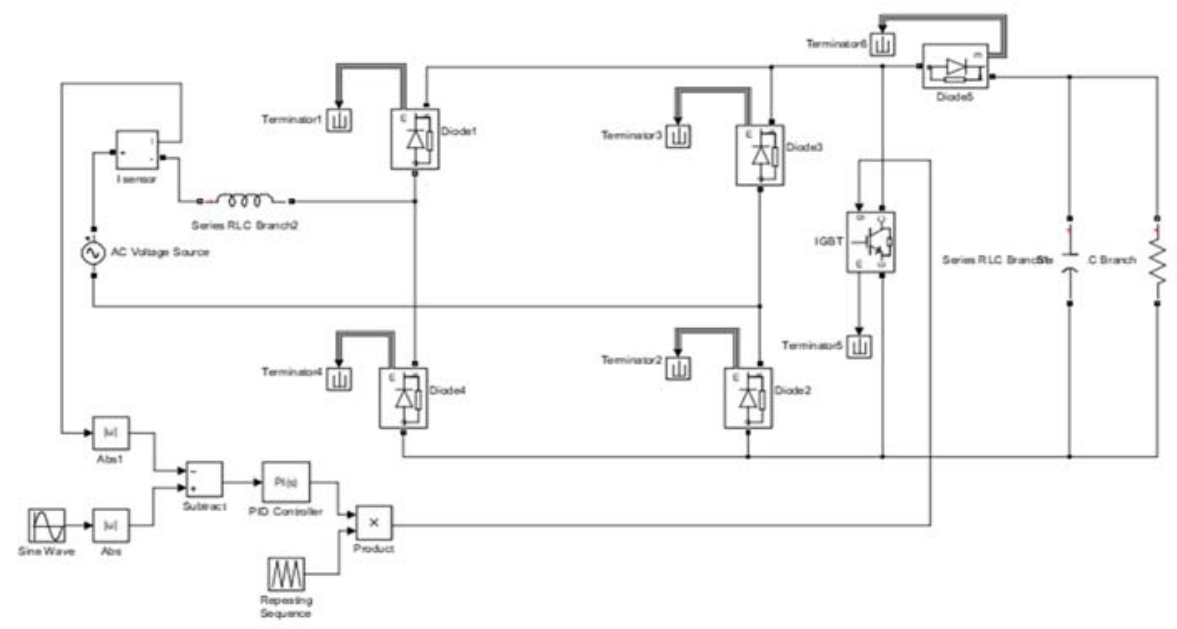

Figure 3. APF circuit with Boost rectifier technique

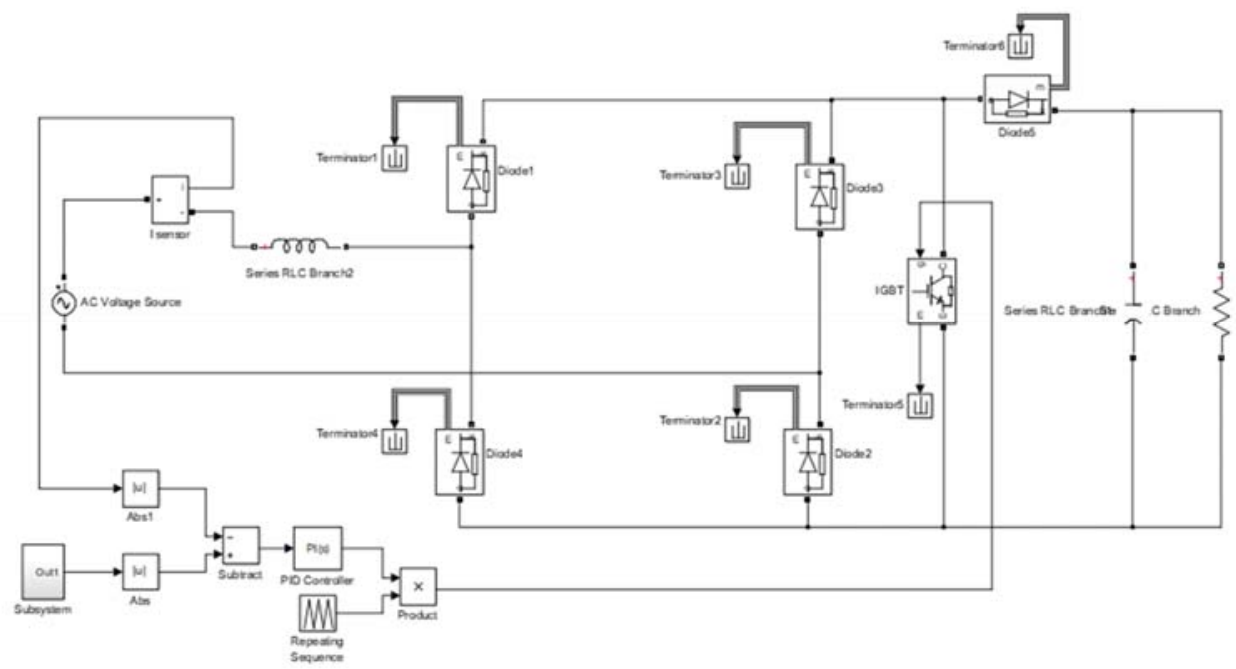

Figure 4. APF with step response function

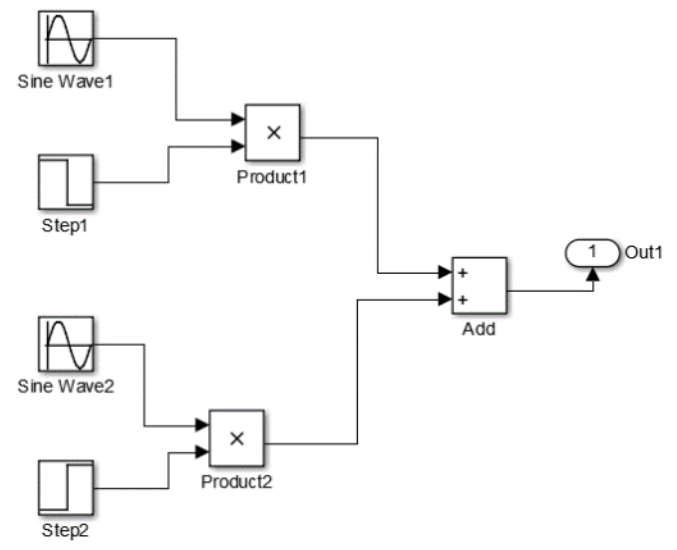

Figure 5. Step Response Controller 


\section{RESULTS AND DISCUSSION}

Figure 6 shows the pulsating supply current waveform which contains a rich of harmonics while Figure 7 shows the comparison of the THD level without filter from the pulsating supply current with the IEEE 519 standard regulation. Since the pulsating supply current violated the IEEE 519 standard regulation, an APF configuration circuit is integrated to the boost rectifier to mitigate the harmonic distortion.

Figure 8 shows the sinusoidal supply current waveform of the proposed APF function, whilst Figure 9 shows that the supply current follows the sinusoidal waveform of reference current when APF is applied. Figure 10 shows that the supply current and voltage waveforms are in-phase, thus increase the power factor.

The comparison result of the THD level without any filter function and with the proposed APF function is as tabulated in Table 2. It shows that the THD value without any filter function is $152.56 \%$, whilst, with the proposed APF function, the THD level was reduces to $1.62 \%$. Thus, it shows that the corrective waveforms was achieved and it complies with IEEE 519 standard as shown in Figure 11.

Figure 12 shows the step response signal with $I_{\text {ref }}$ that represents both current and two different amplitudes for two cycles from $0 \mathrm{~s}$ to $0.04 \mathrm{~s}$ and $0.04 \mathrm{~s}$ to $0.08 \mathrm{~s}$. Technically, it proves that the input line current will entirely follow the sinusoidal reference current.

Table 2. THD level with and without APF function

\begin{tabular}{cc}
\hline Variable & THD $(\%)$ \\
\hline Without APF & 152.56 \\
With APF & 1.62 \\
\hline
\end{tabular}

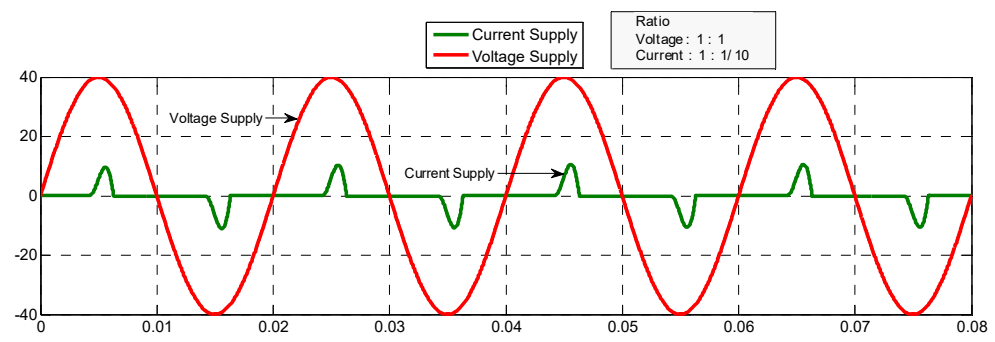

Figure 6 . The pulsating supply current from supply current and supply voltage

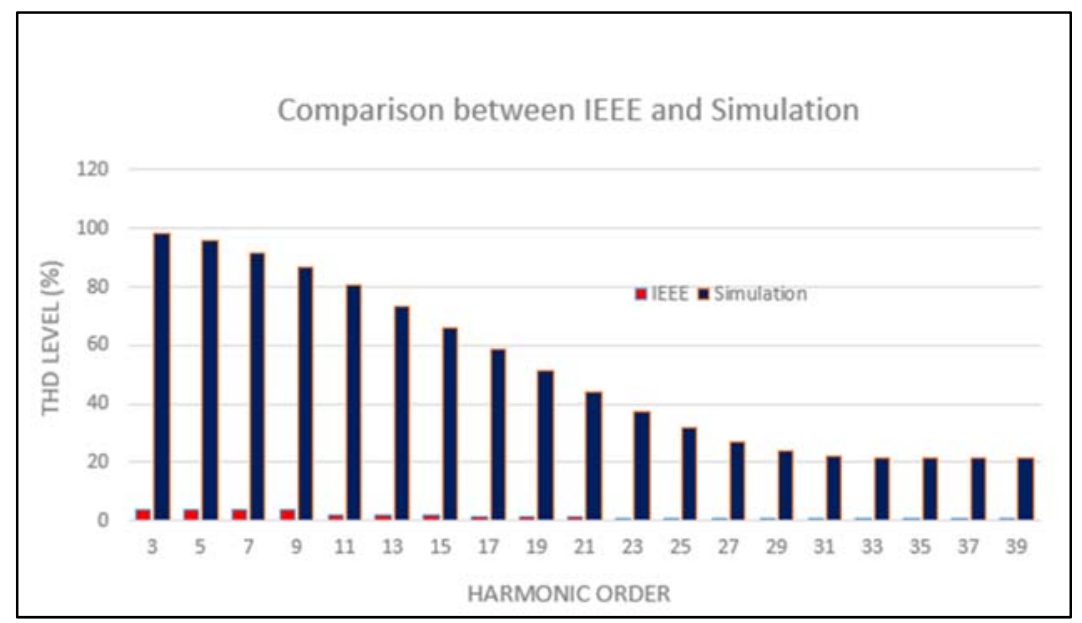

Figure 7. Comparison value for THD level between Simulation and IEEE 519 Standard without filter 


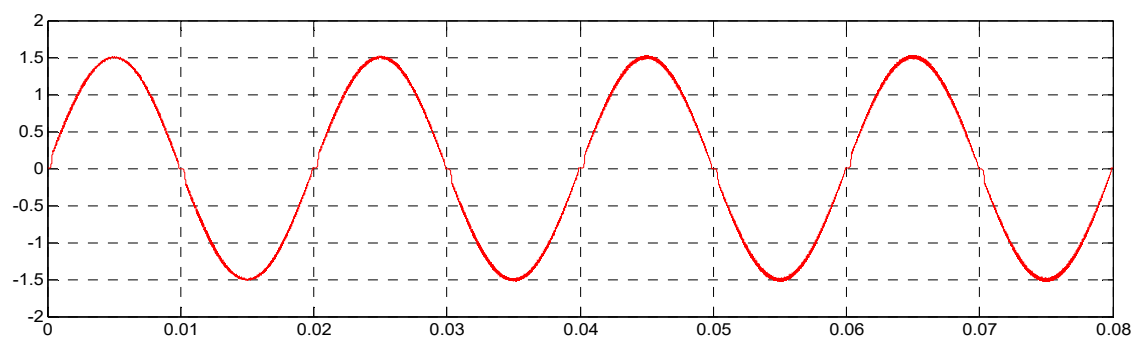

Figure 8. The input supply current waveform

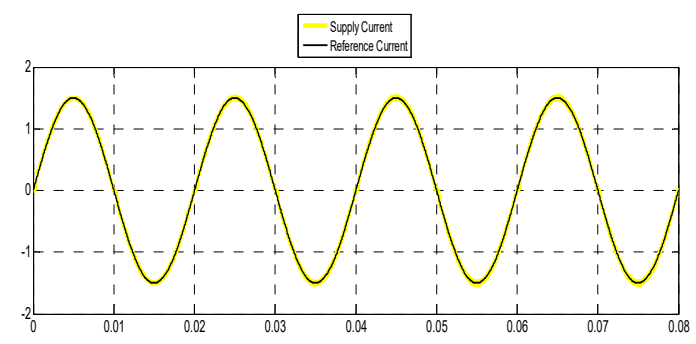

Figure 9. The input supply current with sinusoidal reference current

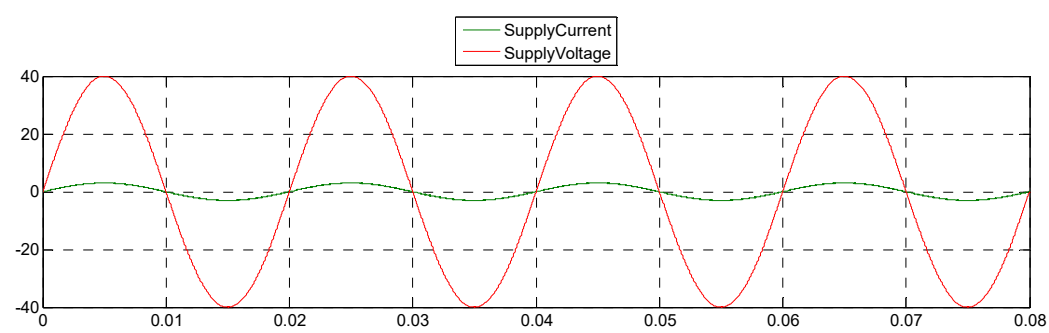

Figure 10. The input supply current and input supply voltage waveforms

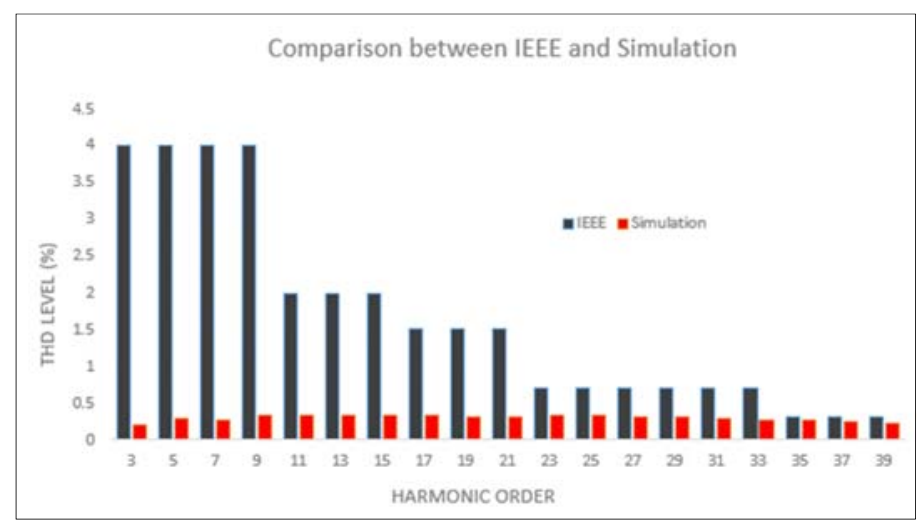

Figure 11. Comparison value for THD level between Simulation and IEEE 519 Standard with filter 


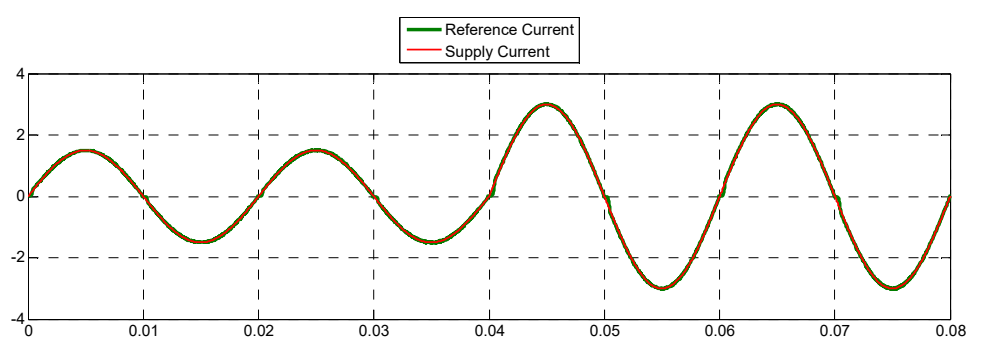

Figure 12. The step response signal with $I_{r e f}=1.5 \mathrm{~A}$ at $0.04 \mathrm{~s}$ and $I_{r e f}=3$ at $0.08 \mathrm{~s}$

\section{CONCLUSION}

In this paper, the proposed APF using boost rectifier technique has been presented. From the evaluation via MATLAB/Simulink, it was found that the THD level of the rectifier converter without filter is higher compared with APF. By using the proposed APF function, we can reduce the THD level, thus, complying with the IEEE 519 standard. Finally, the use of APF circuit configuration can further improve the power quality problems.

\section{ACKNOWLEDGEMENTS}

Authors gratefully acknowledge the financial support from Institute of Research Management and Innovation (IRMI) Universiti Teknologi MARA Grant No: 600-IRMI 5/3/GIP (034/2018).

\section{REFERENCES}

[1] Lei Wang; Chi-Seng Lam; Man-Chung Wong; "Minimizing Inverter Capacity Design and Comparative Performance Evaluation of SVC-Coupling Hybrid Active Power Filters", IEEE Transactions on Power Electronics, vol.34 , no. 2, Pp 1227- 242, 2019.

[2] Wanno Yeetum; Vijit Kinnares; "Parallel Active Power Filter Based on Source Current Detection for Antiparallel Resonance with Robustness to Parameter Variations in Power Systems", IEEE Transactions on Industrial Electronics, vol. 66, no. 2, pp. 876-886, 2019.

[3] Yun Chen; Juntao Fei; "Dynamic Sliding Mode Control of Active Power Filter With Integral Switching Gain", IEEE Access, vol. 7, pp. 21635-21644. 2019.

[4] Phelipe Leal Serafim Rodrigues; Cursino Brandão Jacobina; Maurício Beltrão de Rossiter Corrêa; Italo Roger Ferreira Moreno Pinheiro da Silva; "Single-Phase Universal Active Power Filter Based on Four-Leg AC-DC-AC Converters", IEEE Transactions on Industry Applications, Vol. 55 , No. 2 , pp. 1639-1648, 2019.

[5] Hao Liu; Chi Li; Zedong Zheng; Jiye Liu; Yongdong Li; "Shunt Isolated Active Power Filter With Common DC Link Integrating Braking Energy Recovery in Urban Rail Transit”, IEEE Access, Vol. 7 , pp.39180-39191, 2019.

[6] Asif Raza Jarwar; Amir Mahmood Soomro; Zubair Ahmed Memon; Shafiq Ahmed Odhano; Muhammad Aslam Uqaili; Abdul Sattar Larik; "High dynamic performance power quality conditioner for AC microgrids", IET Power Electronics, vol. 12, no. 3, pp.550-556, 2019.

[7] X. S. Li, et al., "Analysis and Simplification of Three-Dimensional Space Vector PWM for Three-Phase Four-Leg Inverters," IEEE Transactions on Industrial Electronics, vol. 58, pp. 450-464, Feb 2011.

[8] L. Motta and N. Faúndes, "Active / passive harmonic filters: Applications, challenges \& trends," Proc. Int. Conf. Harmon. Qual. Power, ICHQP, vol. 2016, no. 1, pp. 657-662, 2016.

[9] R. Baharom, M. K. M. Salleh, and N. F. A. Rahman, "Active power filter with direct output voltage control of single-phase AC to DC converter,” PECON 2016-2016 IEEE 6th Int. Conf. Power Energy, pp. 412-416, 2017.

[10] W. U. Tareen, S. Mekhilef, M. Seyedmahmoudian, and B. Horan, "Active power filter (APF) for mitigation of power quality issues in grid integration of wind and photovoltaic energy conversion system," Renew. Sustain. Energy Rev., vol. 70, pp. 635-655, 2017.

[11] Marian P. Kazmierkowski; "Power Quality: Problems and Mitigation Techniques", IEEE Industrial Electronics Magazine, 2015, vol. 9, no. 2, pp.62-62, 2015.

[12] A. S. A. Hasim and M. F. Saidon, "Development of a single-phase shunt active power filter using boost rectifier technique," SCOReD 2006-Proc. 2006 4th Student Conf. Res. Dev. pp. 262-265, 2006.

[13] K. Venkitusamy, S. Padmanaban, M. Pecht, A. Awasthi, and R. Selvamuthukumaran, "A modified boost rectifier for elimination of circulating current in power factor correction applications," Microelectron. Reliab., vol. 69, pp. 29-35, 2017.

[14] B. Singh, V. Garg, and G. Bhuvaneswari, "Polygon connected 15-phase AC-DC converter for power quality improvement," 2006 Int. Conf. Power Electron. Drives Energy Syst. PEDES ’06, pp. 3-7, 2006.

Int J Pow Elec \& Dri Syst, Vol. 10, No. 3, Sep 2019 : $1446-1453$ 
[15] Jie Yang; Zhiyuan He; Jinkun Ke; Minhua Xie; "A New Hybrid Multilevel DC-AC Converter With Reduced Energy Storage Requirement and Power Losses for HVDC Applications", IEEE Transactions on Power Electronics, vol. 34, no. 3 , pp. 2082-2096, 2019.

[16] Houqing Wang; Weimin Wu; Yunwei Li; Frede Blaabjerg; "A Coupled-Inductor-Based Buck-Boost AC-DC Converter With Balanced DC Output Voltages”, IEEE Transactions on Power Electronics, vol. 34 , no. 1 , pp.151$159,2019$.

[17] Shakil Ahamed Khan; Youguang Guo; Jianguo Zhu; "Model Predictive Observer Based Control for Single-Phase Asymmetrical T-Type AC/DC Power Converter”, IEEE Transactions on Industry Applications, vol. 55, no. 2, pp. 2033-2044, 2019.

[18] Hongfei Wu; Meng Han; Kai Sun; "Dual-Voltage-Rectifier-Based Single-Phase AC-DC Converters With Dual DC Bus and Voltage-Sigma Architecture for Variable DC Output Applications", IEEE Transactions on Power Electronics, Vol. 34, No. 5, pp.4208-4222, 2019.

[19] H. V. Nguyen and D. C. Lee, "Reduction of DC-link capacitance in bridgeless PFC boost rectifiers," 2015 IEEE 2nd Int. Futur. Energy Electron. Conf. IFEEC 2015, 2015.

[20] B. Singh, V. Garg, and G. Bhuvaneswari, "Third harmonic current injection for power quality improvement in rectifier loads,” 2006 Int. Conf. Power Electron. Drives Energy Syst. PEDES ’06, vol. 00, pp. 1-5, 2006.

[21] A. A. Badeli, R. Baharom, N. Hidayat, and M. K. Hamzah, "Single-phase matrix converter with reduced switch count operating as buck or boost rectifier," ISCAIE 2012-2012 IEEE Symp. Comput. Appl. Ind. Electron. no. Iscaie, pp. 20-25, 2012.

[22] P. Kandasamy, Literature Review on Control Techniques of AC-DC Boost Converter, vol. 118, no. 24. 2018.

[23] M. El-Habrouk, M. K. Darwish, and P. Mehta, "Active power filters: A review," IEE Proc.-Electr. Power Appl., vol. 147 , no. 5 , p. $403,2000$.

[24] P. Sharma, "Analysis of Different Converters for Reduced Total Harmonic Distortion and Improved Power Factor," 2018 5th Int. Conf. Signal Process. Integr. Networks, pp. 608-613, 2018.

[25] J. Anuszczyk and B. Terlecki, "Analysis of electric power quality: A case study: Kamiensk wind power plant," 2009 10th Int. Conf. Electr. Power Qual. Util. EPQU’09, no. 98, 2009. 